\title{
Erythrocyte transketolase activity in patients with diabetic and alcoholic neuropathies
}

\author{
Sławomir Michalak ${ }^{1,2}$, Grażyna Michałowska-Wender ${ }^{2,3}$, Grażyna Adamcewicz ${ }^{4}$, Mieczysław Bogumił Wender ${ }^{2}$ \\ ${ }^{1}$ Department of Neurochemistry and Neuropathology, Poznan University of Medical Sciences, ${ }^{2}$ Neuroimmunological Unit, Mossakowski \\ Medical Research Centre, Poznan, ${ }^{3}$ Laboratory of Neurogenetics, Poznan University of Medical Sciences, ${ }^{4}$ Laboratory of Clinical \\ Neurogenetics, Chair and Clinic of Neurology, Poznań University of Medical Sciences, Poland
}

\begin{abstract}
Introduction: The activity of erythrocyte transketolase induced by thiamine pyrophosphate and normalized to age of the patient is a marker of thiamine metabolism disturbances with pathological consequences in the central and peripheral nervous system. The measurement of erythrocyte transketolase activity enables evaluation of the thiamine status and therapeutic decisions in the disorders of the nervous system related to its deficiency. The aim of the study was to compare different modes of expression of transketolase activity in the most frequent acquired neuropathies.

Material and methods: The study included 29 patients with type 2 diabetes mellitus (21 males, 8 females) aged 48.3 years (range: $20-70$ years) and 31 subjects with a history of alcohol dependence (23 males, 8 females) aged 54.5 years (range: 28-60 years). All participants of the study showed signs and symptoms of neuropathy. The cases in both groups presented the involvement of either axon, myelin, or both, what was evidenced by electrophysiological tests (electromyography and estimation of nerve conduction velocity). The control group consisted of 20 healthy persons aged 49.1 years (range: 23-70 years). Transketolase activity in erythrocytes (TK) was assessed by means of the spectrophotometric method. Basic TK activity was expressed as units per gram of haemoglobin ( $\mathrm{g} \mathrm{Hb}$ ), moreover the normalized transketolase activity ratio (NTKZ) and percentage of activation of thiamine pyrophosphate (TPP) were calculated.

Results: The basal TK activity was decreased in cases with diabetic neuropathy $(0.64 \pm 0.342 \mathrm{U} / \mathrm{g} \mathrm{Hb}, p=0.0131)$, whereas in patients with alcoholic neuropathy only a trend $(p=0.058)$ of the decrease was noticed $(0.85 \pm 0.484 \mathrm{U} / \mathrm{g} \mathrm{Hb})$, in relation to the control group $(1.005 \pm 0.390 \mathrm{U} / \mathrm{g} \mathrm{Hb})$. Normalized transketolase activity ratio in erythrocytes has not shown any statistically significant differences. The median TPP did not indicate any thiamine deficiency, both in the group of diabetic and alcoholic neuropathy.

Conclusions: The decrease in transketolase activity in diabetic neuropathy may be independent of thiamine deficiency. Abnormalities in transketolase activity, when expressed in three modalities: basal activity, normalized transketolase activity ratio and the activity after the stimulation with thiamine pyrophosphate may be differentiated as thiamine-dependent or resulting from posttranslational modification.
\end{abstract}

Key words: transketolase, diabetic neuropathy, alcoholic neuropathy. 


\section{Introduction}

Transketolase (TK), a thiamine diphosphate-dependent enzyme, catalyses several key reactions of the non-oxidative branch in the pentose phosphate pathway. One of important reactions catalyzed by transketolase is the conversion of the pentose sugars, ribose and xylulose, to a seven-atom sugar, sedoheptulose and glycerol aldehyde phosphate. TK is a homodimer with active sites at the interface between the contacting monomers [25]. Activity of erythrocyte's transketolase induced by thiamine pyrophosphate and normalized to age of the patient is a marker of thiamine metabolism disturbances with pathological consequences in the central and peripheral nervous system [3]. The activity of transketolase in a spectrum of neurological disorders has been studied for decades, however new data are continuously published, which reveal new aspects with a potential application in clinical settings. A novel field of research on transketolase is related to cancer. Transketolase is involved in the non-oxidative branch of the pentose phosphate pathway that generates the ribose for nucleic acid synthesis. Because this pathway is up-regulated in cancer cells, transketolase is recognized as a target for novel chemotherapeutics [18]. Thus, thiamine antagonists were designed to inhibit transketolase activity $[13,22,23]$. If effective, this treatment may cause neurological complications. Recently, an experimental study has shown a positive, dose-dependent effect of flunarizine on the cisplatin-induced tissue biochemical changes including transketolase activity in the model of neuropathy [16]. Thus, transketolase may be considered as a therapeutic target not only for thiamine containing drugs and the evaluation of its activity remains an important biomarker in a spectrum of conditions.

The pathophysiology of diabetic and alcoholic neuropathies is complex and depends on the clinical history of habits as well as previous treatment. Transketolase is still considered as an important component of pathomechanisms involved in diabetic and alcohol neuropathy and supplementation with thiamine pyrophosphate, a cofactor for transketolase activity is suggested to have a protective effect against neuropathy [1]. Thiamine deficiency has been until now considered among other phenomena observed in the course of alcoholic neuropathy including activation of spinal cord microglia, oxi- dative stress, activation of mGlu5 receptors in the spinal cord and activation of the sympathoadrenal and hypothalamo-pituitary-adrenal axis [4]. On the other hand, there are cases supplemented intensively with thiamine and showing a marginal deficit of thiamine. Thus, the assay of TK with and without stimulation of thiamine pyrophosphate may elucidate that problem.

With this background in mind we have undertaken a study on the activity of erythrocyte's transketolase in patients with diabetic and alcoholic neuropathies. The aim of the study was to compare different modes of expression of transketolase activity in the most frequent acquired neuropathies.

\section{Material and methods}

The demographic and clinical characteristics of studied populations of diabetic, alcohol-dependent patients and controls are presented in Table I. No differences between the age of diabetics and controls $(p=0.656)$, alcohol-dependent patients and controls $(p=0.786)$, as well as between diabetics and alcohol-dependent patients $(p=0.421)$ were found.

Clinimetric evaluation of severity of neuropathic symptoms was scored basing on Katzenwadel scale [10], which evaluates muscle strength, reflexes, co-ordination of movements, sensation and pain. The cases in both groups presented the involvement of either axon or myelin, or both, what was evaluated by electrophysiological tests (electromyography and estimation of nerve conduction velocity).

Diabetic patients with coexisting disorders like nephropathy, chronic kidney disease, renal insuffi-

Table I. Demographic and clinical characteristics of studied groups

\begin{tabular}{|lccc|}
\hline & $\begin{array}{c}\text { Control } \\
\text { group } \\
\end{array}$ & $\begin{array}{c}\text { Diabetic } \\
\text { neuropathy }\end{array}$ & $\begin{array}{c}\text { Alcoholic } \\
\text { neuropathy }\end{array}$ \\
& $\mathbf{n = 2 0}$ & $\boldsymbol{n}=\mathbf{2 9}$ & $\mathbf{n 1}$ \\
\hline Gender, F/M (\%) & $16 / 4(80 / 20)$ & $8 / 21(28 / 72)$ & $8 / 23(26 / 74)$ \\
\hline Age, mean & $49.1(23-70)$ & $48.3(20-70)$ & $54.5(28-60)$ \\
(range) [years] & & & \\
\hline Katzenwadel & Not & $0-0 \%$ & $0-0 \%$ \\
scale scoring & applicable & $1-7 \%$ & $1-6 \%$ \\
& & $2-10.5 \%$ & $2-30.5 \%$ \\
& & $3-17 \%$ & $3-9 \%$ \\
& & $4-34 \%$ & $4-30.5 \%$ \\
& & $5-21 \%$ & $5-15 \%$ \\
& & $6-9-10.5 \%$ & $6-9-9 \%$ \\
\hline
\end{tabular}


ciency, acute or chronic pancreatitis, liver dysfunction/cirrhosis and vitamin supplementation were not included in the study.

The comorbidities such as diabetes, acute or chronic pancreatitis, nephropathy, chronic kidney disease, renal insufficiency, active liver dysfunction/cirrhosis and vitamin supplementation were exclusion criteria in the group of alcohol-dependent patients.

Transketolase activity in erythrocytes (TK) was assessed by means of the spectrophotometric method [20], modified by Bayoumi [2] and expressed as units per gram of haemoglobin ( $\mathrm{g} \mathrm{Hb}$ ). The age-dependent transketolase activity (normalized transketolase activity ratio, NTKZ) was calculated as follows:

$$
\text { NTKZ }=\frac{\text { TK }}{[0.6066-(0.002045 \times \text { age })]}[\mathrm{U} / \mathrm{g} \mathrm{Hb}],
$$

where $T K$ is activity of transketolase in erythrocytes, $\mathrm{U} / \mathrm{g} \mathrm{Hb}$ is units/g of haemoglobin, NTKZ is normalized transketolase activity ratio in erythrocytes.

The percentage of activation of thiamine pyrophosphate (TPP) was calculated as follows:

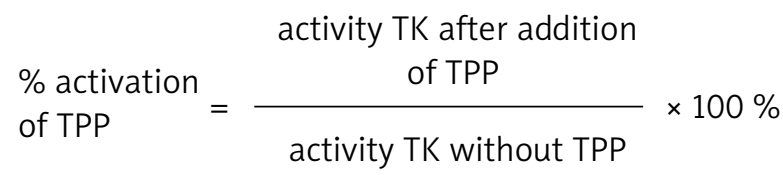

Normal value: $0-15 \%$.

$\%$ of TPP activation > 15\% demonstrates thiamine (vitamin $B_{1}$ ) deficit.

One unit of transketolase produces $1.0 \mu \mathrm{mol}$ of glyceraldehyde 3-phosphate from xylulose 5-phospha-

Table II. The activity of erythrocyte's transketolase in patients with diabetic and alcoholic neuropathy

\begin{tabular}{|lccc|}
\hline & $\begin{array}{c}\text { Control group } \\
n=20\end{array}$ & $\begin{array}{c}\text { Diabetic neu- } \\
\text { ropathy } \\
n=29\end{array}$ & $\begin{array}{c}\text { Alcoholic } \\
\text { neuropathy } \\
n=31\end{array}$ \\
\hline $\begin{array}{l}\text { TK } \\
{[\mathrm{U} / \mathrm{g} \mathrm{Hb}]}\end{array}$ & $1.005 \pm 0.396$ & $0.642 \pm 0.342^{*}$ & $0.853 \pm 0.484^{+}$ \\
\hline $\begin{array}{l}\mathrm{NTKZ} \\
{[\mathrm{U} / \mathrm{g} \mathrm{Hb}]}\end{array}$ & $1.963 \pm 0.742$ & $1.332 \pm 0.699$ & $1.648 \pm 0.936$ \\
\hline $\begin{array}{l}\% \text { of TPP } \\
\text { activity }\end{array}$ & 0.0 & 0.0 & 0.0 \\
\hline
\end{tabular}

${ }^{*} p=0.001,{ }^{+} p=0.058$ te per minute at $25^{\circ} \mathrm{C}$, in the presence of ribose 5 -phosphate, thiamine pyrophosphate and $\mathrm{Mg}^{2+}$ using a coupled system with $\alpha-G D H / T P I$.

Haemoglobin was measured in a portion of erythrocyte hemolysate upon conversion to methaemoglobin [5].

\section{Results}

The cases with diabetic neuropathy demonstrated a decreased transketolase activity, whereas in patients with alcoholic neuropathy only a trend of the decrease was noticed, in relation to the control group (Table II). The normalized transketolase activity in erythrocytes has not shown any statistically significant differences. The median percentage of transketolase activity after the stimulation with thiamine pyrophosphate did not indicate thiamine deficiency both in the group of diabetic and alcoholic neuropathy (Table II).

Basal transketolase activity and the percentage of transketolase activity after the stimulation with thiamine pyrophosphate did not correlate with age in the group of diabetic and alcoholic neuropathy. We also did not find any effect of gender on TK, NTKZ or transketolase activity after the stimulation with thiamine pyrophosphate in all studied groups. Thus, down-regulation of transketolase activity observed in our study seems to be a result of posttranslational modification that is independent of thiamine deficiency, age and gender.

\section{Discussion}

Transketolase activity in erythrocytes was explored in patients with diabetic and alcoholic neuropathy with consideration to modes of expression including the basal activity, normalized transketolase activity ratio and transketolase activity after the stimulation with thiamine pyrophosphate. Basal TK activity was decreased in diabetic neuropathy patients without any indication of thiamine deficiency.

Pathomechanisms related with metabolic disturbances behind diabetic neuropathy are not limited to the effect of hyperglycaemia, but involve also the deficiency of insulin and C-peptide, leading to disturbances of neurotrophic factors [19]. As a result, degeneration of axons is mediated by direct metabolic disturbances and by insufficiency of microvascular circulation. Experimental studies supported the hypothesis that activation of the receptor for 
advanced glycation end product (RAGE) is one of the first steps in pathogenesis of diabetic neuropathy [7]. Immunological studies [15] revealed the impact of growth-regulated oncogene $\alpha$ (GRO a - CXCL-1) in the mechanism of the demyelinating form of diabetic neuropathy, probably mediated by a host CXC receptor-2 dependent pathway. The decreased basal activity of transketolase found in our study along with normal NTKZ and normal transketolase activity after the stimulation with thiamine pyrophosphate in patients with diabetic neuropathy indicated the posttranslational down-regulation independent of thiamine deficiency. The mechanisms considered in posttranslational modification of transketolase activity include oxidative stress. In vitro studies revealed the effect of oxidation on TK activity [24]. Posttranslational modification of TK activity may also result from autoimmune reaction directed against the enzymatic protein. TK has been shown to be recognized by immunoglobulins $\mathrm{G}$ in multiple sclerosis patients [14]. In experimental diabetes, an impaired activity of transketolase results in depletion of reducing agents and accumulation of glycation end-products (AGE) leading to deleterious effects for endothelial cells that can be reversed by transketolase stimulation [9]. In the model of insulin resistance, the transketolase activity was decreased in rats fed with a high-fructose diet with chromium supplementation, however it was up-regulated in animals on high-fructose feeding alone and with thiamine supplementation [11]. Moreover, the accumulation of AGE and oxidative stress in diabetic patients is alleviated by up-regulation of transketolase activity [21]. Thus, the stimulators of transketolase activity e.g. benfotiamine showing anti-oxidant effect [21] may be considered in clinical settings.

The pathogenesis of alcoholic neuropathy includes a direct toxic effect of alcohol consumption on peripheral nerves and indirect consequences caused by impairment of the liver function, malabsorption and as well as maldigestion of nutritional factors [12,17]. The studies on the effects of liver cirrhosis on transketolase activity provide equivocal results ranging from inhibitory influence of the liver dysfunction on TPP stimulation of TK activity [6] to no effects [8]. That was the rationale for exclusion of patients with an active liver dysfunction and liver cirrhosis from our study. In our study, transketolase activity showed only a trend of the decrease, but still without markers of thiamine deficiency. Down-regulation of transketolase activity, as suggested in our study, may be one of possible pathomechanisms of alcoholic neuropathy. Oxidative stress observed along with other disturbances in alcohol-dependent patients and related to decreased transketolase activity constitutes the therapeutic target.

To conclude, our study has established a decrease in transketolase activity in diabetic neuropathy, without any indication of thiamine deficiency. In contrast to the significant decrease in basal transketolase activity in patients with diabetic neuropathy, an unexpected insignificant trend for lowering TK activity in alcoholic neuropathy was found. The application of transketolase activity tests is not used as widely as it may be expected basing on experimental and clinical studies. We suggest that abnormalities in transketolase activity, when expressed in three modalities: basal activity, NTKZ and activity after the stimulation with thiamine pyrophosphate may be differentiated as thiamine-dependent or resulting from posttranslational modification. The TK estimation should be thus considered as the golden standard, before initiation of the thiamine/benfotiamine substitution, as an element of pathogenesis-oriented, tailored therapy.

\section{References}

1. Alcázar-Leyva S, Alvarado-Vásquez N. Could thiamine pyrophosphate be a regulator of the nitric oxide synthesis in the endothelial cell of diabetic patients? Med Hypotheses 2011; 76 : 629-631.

2. Bayoumi RA, Rosalki SB. Evaluation of methods of coenzyme activation of erythrocyte enzymes for detection of deficiency of vitamins B1, B2, and B6. Clin Chem 1976; 22: 327-335.

3. Brin M. Erythrocyte as a biopsy tissue for functional evaluation of thiamine adequacy. JAMA 1964; 187: 762-766.

4. Chopra K, Tiwari V. Alcoholic neuropathy: possible mechanisms and future treatment possibilities. Br J Clin Pharmacol 2012; 73 : 348-362.

5. Drabkin DL, Austin JH. Spectrophotometric studies: I. Spectrophotometric constants for common hemoglobin derivatives in human, dog, and rabbit blood. J Biol Chem 1932; 98: 719-733.

6. Fennelly J, Frank O, Baker H, Leevy CM. Red blood cell-transketolase activity in malnourished alcoholics with cirrhosis. Am J Clin Nutr 1967; 20: 946-949.

7. Haslbeck KM, Schleicher E, Bierhaus A, Nawroth P, Haslbeck M, Neundörfer B, Heuss D. The AGE/RAGE/NF-(kappa)B pathway may contribute to the pathogenesis of polyneuropathy in impaired glucose tolerance (IGT). Exp Clin Endocrinol Diabetes 2005; 113: 288-291.

8. Graudal N, Torp-Pedersen K, Bonde J, Hanel HK, Kristensen M, Milman N, Thomsen AC. The influence of hepatic insufficiency due to alcoholic cirrhosis on the erythrocyte transketolase activity (ETKA). Liver 1987; 7: 91-95. 
9. Katare R, Caporali A, Emanueli C, Madeddu P. Benfotiamine improves functional recovery of the infarcted heart via activation of pro-survival G6PD/Akt signaling pathway and modulation of neurohormonal response. J Mol Cell Cardiol 2010; 49 625-638.

10. Katzenwadel A, Sachse G, Federlin K. Messung von Vibrationsempfinden und Temperaturdiskrimination bei der peripheren diabetischen Neuropathie. Akt Endokrin Stoffw 1987; 8: 155160.

11. Król E, Krejpcio Z, Michalak S, Wójciak RW, Bogdański P. Effects of Combined Dietary Chromium(III) Propionate Complex and Thiamine Supplementation on Insulin Sensitivity, Blood Biochemical Indices, and Mineral Levels in High-Fructose-Fed Rats. Biol Trace Elem Res 2012; 150: 350-359.

12. Kucera P, Balaz M, Varsik P, Kurca E. Pathogenesis of alcoholic neuropathy. Bratisl Lek Listy 2002; 103: 26-29.

13. Le Huerou Y, Gunawardana I, Thomas AA, Boyd SA, de Meese J, Dewolf W, Gonzales SS, Han M, Hayter L, Kaplan T, Lemieux C, Lee P, Pheneger J, Poch G, Romoff TT, Sullivan F, Weiler S, Wright SK, Lin J. Prodrug thiamine analogs as inhibitors of the enzyme transketolase. Bioorg Med Chem Lett 2008; 18 505-508.

14. Lovato L, Cianti R, Gini B, Marconi S, Bianchi L, Armini A, Anghileri E, Locatelli F, Paoletti F, Franciotta D, Bini L, Bonetti B. Transketolase and 2',3'-cyclic-nucleotide 3'-phosphodiesterase type I isoforms are specifically recognized by IgG autoantibodies in multiple sclerosis patients. Mol Cell Proteomics 2008; 7: 2337 2349.

15. Michałowska-Wender G, Adamcewicz G, Wender M. Impact of cytokines on the pathomechanism of diabetic and alcoholic neuropathies. Folia Neuropathol 2007; 45: 78-81.

16. Muthuraman A, Singla SK, Peters A. Exploring the potential of flunarizine for Cisplatin-induced painful uremic neuropathy in rats. Int Neurourol J 2011; 15: 127-134.

17. Neundörfer B. Alcohol polyneuropathy. Fortschr Neurol Psychiatr 2001; 69: 341-345.

18. Obiol-Pardo C, Alcarraz-Vizán G, Cascante M, Rubio-Martinez J. Diphenyl urea derivatives as inhibitors of transketolase: a structure-based virtual screening. PLoS One 2012; 7: e32276. Epub 2012 Mar 5.

19. Pierson CR, Zhang W, Murakawa Y, Sima AA. Insulin deficiency rather than hyperglycemia accounts for impaired neurotrophic responses and nerve fiber regeneration in type 1 diabetic neuropathy. J Neuropathol Exp Neurol 2003; 62: 260-271.

20. Smeets EH, Muller H, de Wael J. A NADH-dependent transketolase assay in erythrocyte hemolysates. Clin Chim Acta 1971; 33: 379-386.

21. Schmid U, Stopper H, Heidland A, Schupp N. Benfotiamine exhibits direct antioxidative capacity and prevents induction of DNA damage in vitro. Diabetes Metab Res Rev 2008; 24: 371-377.

22. Thomas AA, De Meese J, Le Huerou Y, Boyd SA, Romoff TT, Gonzales SS, Gunawardana I, Kaplan T, Sullivan F, Condroski K, Lyssikatos JP, Aicher TD, Ballard J, Bernat B, DeWolf W, Han M, Lemieux C, Smith D, Weiler S, Wright SK, Vigers G, Brandhuber B. Non-charged thiamine analogs as inhibitors of enzyme transketolase. Bioorg Med Chem Lett 2008; 18: 509-512.
23. Thomas AA, Le Huerou Y, De Meese J, Gunawardana I, Kaplan T, Romoff T, Gonzales SS, Condroski K, Boyd SA, Ballard J, Bernat B, DeWolf W, Han M, Lee P, Lemieux C, Pedersen R, Pheneger J, Poch G, Smith D, Sullivan F, Weiler S, Wright SK, Lin J, Brandhuber B, Vigers G. Synthesis, in vitro and in vivo activity of thiamine antagonist transketolase inhibitors. Bioorg Med Chem Lett 2008; 18: 2206-2210.

24. Yurshev VA, Sevostyanova IA, Solovjeva ON, Kocheto GA. Inhibition of Transketolase by Hexacyanoferrate(III). Biochemistry (Moscow) 2010; 75: 1014-1016.

25. Zhao J, Zhong CJ. A review on research progress of transketolase. Neurosci Bull 2009; 25: 94-99. 